from which uranium and other prescribed substances might be obtained, the right of working and powers of control over the working of any such minerals.

A further clause in the Bill restricts the disclosure, without the consent of the Minister, of information concerning any existing or proposed plant for producing or using atomic energy, the purpose or method of operation of any such plant or process, exeept plant designed solely for research or educational purposes. This power clearly is required as a preliminary to the ordered release of information. Similarly, the scheme outlined by the Lilienthal Board should remove the fear that scientific research at the universities may be hampered in spite of the specific exception already noted. This is probably the most substantial criticism that can be advanced against the general terms of the Bill; but it needs to be remembered that the Atomic Energy Bill, like similar legislation in the United States, while in one respect preparing the way for an international authority, in itself leaves the matter in the most dangerous position. The dangerous aspects of atomic energy must be taken out of national hands and placed in international hands quickly; and the longer the delay in establishing such an authority the greater the danger, not merely of an uncontrollable atomic armament rivalry between the nations being precipitated, but also the greater the difficulties of the transition period, to which the Lilienthal Board directs special attention.

Here, of course, we are largely entering the political field, as distinct from the technical or scientific, but the man of science or technician has a perfect right to give his views on the political conditions in which any scheme for international control can function successfully. This the Lilienthal Board has done, and there lies upon their fellow men of science the responsibility not merely of scrutinizing the technical aspects of the plan but also of ensuring that those essential political considerations, as well as the broad technical features of the scheme, are fully understood by their fellow citizens. No plan such as is proposed could wisely be undertaken unless there were valid hope that it would be entered into, and carried through, in good faith; and that in itself presupposes public understanding of the indispensable requirements of the plan.

No part of its report is more praiseworthy than that in which the Lilienthal Board endeavours to prepare public opinion in the United States for the implications of any such scheme, and the disappear. ance of the present monopoly, both in knowledge and in physical facilities. Scientific workers already recognize that knowledge will become general ; for the science on which the release of atomic energy rests is essentially a world-wide science, to which men of many countries have contributed, and the principal findings on which the success of the project depends are well known to workers in the field of nuclear physics everywhere. Further, the ultimate balance towards which a plan for international control must work will witness the loss also of material facilities, so that neither in legal possession nor in grographical distribution is any one nation unduly favoured.
But there is one point here that should be made plain. The Lilienthal Board, in proposing an international authority, is using the word in a particular sense - that of a super- or extra-national body. It does not advocate the disclosure of the critical items of fundamental knowledge or of the technique of production to national governments in the way that immediate disclosure to the United Nations Organisation would involve. What it proposes is an impartial body standing outside and above national rivalries and suspicions; and there is sound reason for the United States or Canada or Great Britain declining to impart the essential information of this type to any other body. It seems clear from the Atomic Scientists Association's memorandum that this view is shared by British men of science also, and Dr. Wimperis in his book quotes an emphatic opinion to the same effect from Prof. A. Einstein. Until the individual nations are prepared to renounce national sovereignty to that limited extent, atomic energy will continue to represent the great menace of our age, and its potentialities for good will remain an unsubstantial shadow.

${ }^{1}$ A Report on the International Control of Atomic Energy. Prepared for the Secretary of State's Committee on Atomic Energy by a Board of Consultants, Washington, D.C. Pp. viii +44 . (Washington, D.C.: Government Printing Office; London: H.M. Stationery Office, 1946.) 18. net.

${ }^{2}$ World Power and Atomic Energy: the Impact on International Relations. By H. E. Wimperis. Pp. viii $+87+5$ plates. (London : Constable and Co., Ltd., 1946.) 68. net.

3 The Era of Atomic Power. Report of a Commission appointed by the British Council of Churches. Pp. 84. (London: Student Christian Movement Press, 1946.) 28. net.

\section{STAFFING OF TECHNICAL SCHOOLS AND COLLEGES}

$\mathrm{T}$ HE first post-war report of the Burnham Com mittee on the scales of salaries to be paid to teachers in technical colleges and institutes, art colleges and schools, was published in August 1945. The scales recommended in that report by the Com. mittee, which is comprised of representatives of local education authorities and teachers, were approved by the Minister of Education and are in process of application to the staffs of all technical institutions throughout England and Wales which are supported by grants from the Ministry.

The compromise agreement between local education authorities and teachers set out in detail in the report covers a relatively short period of three years from April 1, 1945, and consequently will be due for review before April 1, 1948. It is not, therefore, too early to consider the question of the adequacy of the salary scales, having regard to the vital importance to Britain of the maintenance and development of a highly efficient system of technical education.

Since the Burnham Report was published, the recommendations of the Committee presided over by Lord Eustace Percy on higher technological education in universities and technical colleges have bəen published. The findings of the Percy Committee make it clear that the higher work carried on in technical colleges, though differing in outlook and objective from that in the faculties of technology of the universities, is by no means inferior to it or of less 
importance. They are parallel systems of higher education, both essential in their respective spheres for the scientific and industrial progress of Great Britain. It follows as a necessary corollary that the staff recruited to the larger technical colleges responsible for the higher branches of technology should not be inferior to those of the technological departments of the universities.

This was recognized by the McNair Committee on the Training of Teachers, the report of which, pub. lished in 1944, stated that the head of a large department of a technical college is doing work, and has responsibilities as regards organisation and research, comparable with those of a university professor. His maximum salary should be of the order of that of a university professor.

From Circulars recently issued to local education authorities by the Minister of Education, notably Nos. 87, 94 and 98, it is evident that the Minister is prepared to be guided by the recommendations of the Percy Report in the administration of technical education. For example, as recommended in the Percy Report, Circular 87 foreshadows the division of the country into regions for the organisation of further education. Each region is to have a regional advisory council, together with a regional academic board for advanced technology, assisted by advisory committees. The function of the regional academic board is to develop and co-ordinate higher technological studies within the region. Ultimately, a national council of technology is to be brought into being. Upon these bodies representatives of universities, technical colleges and local education authorities will serve. Circular 94 stresses the importance to the industrial progress of Britain of the greater development of research in technical colleges, and makes provision for qualified members of the teaching staff to devote more time to original research than has been possible hitherto. Circular 98 raises the important question of the status of technical colleges, and makes recommendations as to ways and means of increasing the confidence of industry, commerce and the professions in the work of the colleges. It is stipulated that, subject to the ultimate control in matters of finance and general policy by the providing authority, a technical college should enjoy such freedom as will enable the governing body to develop its work in such directions as prove desirable and to attract first-class teachers to its staff. It is added that the provisions of the report of the Burnham Committee on Salaries for Teachers in Technical Colleges, etc., will, the Minister believes, make it possible to offer the emoluments necessary to maintain a high standard of staffing.

This last statement raises an important and crucial issue. It must be said at once that the very comprehensive character of the Burnham scales for technical teachers militates against their effectiveness in the realm of higher technology. The scales for technical teachers have, for reasons which it is not easy to understand, been closely tied to those applicable to teachers in primary and secondary schools. For the large majority of teachers in technical institutions they are in fact identical with them, and only in the provision of separate scales for heads of departments in technical colleges and the introduction of a senior assistant scale for a limited number of technical teachers do they differ from the school salaries. The scales are designed to cover the whole range of further education from the teachers in a small country technical institute to the lecturer in a major technical college, the junior lecturer in which, however advanced and important his work, may be on the same salary scale as the teacher in the smallest institution.

The small addition of $£ 15$ to the minimum and of $£ 30$ to the maximum of the scale in the case of a school teacher possessing a university degree has been the subject of much controversy. Whatever justification-if justification there be-for making this addition to the graduate school teacher's salary so meagre, there surely can be no justification whatever for so miserly a policy in the case of a technical college lecturer, whose fitness for his job depends in many cases on his possessing a university degree or an equivalent professional, industrial or commercial qualification. It is true that the Burnham Report provides for special additions to the basic scales, of $£ 50-£ 100$ inclusive of the graduate allowance in respect of special responsibility, special academic, professional, industrial or commercial qualification; but similar additions are also available to school teachers, and in many areas more liberally to teachers in secondary schools. The fact remains that some 50 per cent of the staff of technical colleges receive no such additions, but are paid on the basic scale common to all teachers. The salaries of senior assistants and heads of departments in technical colleges range from minima of $\mathfrak{£} 600$ for men and $\mathfrak{\$ 4 8 0}$ for women to maxima of more than $£ 1,000$ for men and $£ 800$ for women. The maxima for heads of departments have been fixed by one large local authority at $£ 1,100$ for men and $£ 880$ for women. It can scarcely be claimed that these salaries are comparable with the salaries paid to university professors, as recommended by the MeNair Report. The minimum salaries paid to university professors are now of the order of $£ 1,500$. Moreover, it is understood that the salary to be paid to the principal of one of the largest and most important technical colleges in Great Britain is $£ 1,750$.

Insufficient time has elapsed to determine the effect of the Burnham scales on recruitment to the staffs of the major technical colleges, but it must be obvious that considerable improvement will be needed if really first-class highly qualified men and women with suitable training and experience are to be obtained. For the successful development of industry and commerce, the training of key technologists, industrial research workers and commercial experts should be carried on by the most highly skilled and competent men and women available, who must, if they are to be attracted to the teaching profession, receive adequate financial reward comparable with that obtainable in the universities and in industry and commerce.

The commencing salaries of lecturers in depart. ments dealing with higher technology must be such 
as will attract highly capable men and women who, by further study and research, will be able to keep abreast of the rapid advances in technological development. The salaries of the higher posts to which they can aspire in the profession must be such as to afford them every encouragement both in their teaching and in the important contribution they can make to technological advancement. Moreover, the buildings in which they work and the facilities provided for both teaching and research must be of the very best.

It is very much open to question whether the administration of higher technical education through local education authorities, occupied as they must be with the vast developments of education in the schools provided for in the Education Act of 1944 and with the wider aspects of further education, can ever meet the future needs of Britain in technology and commerce. The Minister of Education has undoubtedly taken a wise step in calling for the establishment of a national council of technology and regional boards. Upon these bodies there must be the strongest possible representation of both industry and commerce, of the technical colleges, and the universities. The needs of the country must be voiced by these bodies, and ways and means must be found quickly for the large financial provision which will be needed if we are to make provision for the very best technological education it is possible to have. Only the best will do.

The time has surely arrived when technological education should no longer be financed by local education authorities aided by a 50 per cent grant from the Exchequer. Something on a national basis akin to the University Grants Committee is needed to deal with this vital part of the educational system of Britain. The administration and development of the larger colleges should no longer be in the hands of the local education authorities, who have quite enough to do to implement the vast provisions of the Education Act in other spheres of education. The methods of administration most suited to the organisation of schools and the more elementary forms of further education do not lend themselves to the efficient control and development of higher technological education, which requires personnel with suitable special experience at both administrative and executive levels. The larger technical colleges should, like the universities, become autonomous bodies receiving grants direct from a national committee of experts suitably qualified to assess and make provision for their needs. Until the control of the more advanced technological education is made a national concern and is in the hands of those most qualified to deal with it, we cannot expect that progress for which the country waits.

A sound system of technological education in Great Britain is a matter of fundamental importance to industry and commerce, and doubtless once it is under efficient national control there will be no lack of grants forthcoming, from private benefactors and from large industrial and commercial undertakings for specific purposes, similar to those received by the universities.

\section{INDUSTRIAL USES OF NATURAL FATS AND FATTY OILS}

\section{Industrial Oil and Fat Products}

By Alton E. Bailey. Pp. $x+735$. (New York : Interscience Publishers, Inc., 1945.) 10 dollars.

$\mathrm{N}$ ATURAL fats and fatty oils derived from vegetable and animal sources are used annually to the extent of many millions of tons in a variety of industries which may be classified in three broad groups: (a) the edible-fat industries (dairy butter, margarine, cooking fats, confectionery fats) ; (b) the manufacture of detergents (soaps of various types, sulphated higher fatty alcohols and other detergents which are not simple alkali salts of fatty acids); (c) the manufacture of paints, varnishes, leather coverings or fillings, linoleum, certain plastics, etc., which depend upon the transformation of certain (unsaturated) fatty oils to colloid-like solids by oxidation and/or polymerization.

The technical processes and plant involved in these different applications of natural fats are many in number and often intricate and elaborate in design. This is perhaps the reason why many monographs on the fat industries are almost entirely occupied with detailed considerations of processing and plant construction, but have frequently paid remarkably little attention to the two features of obvious fundamental importance in a natural raw material. These features are, first, the chemical constitution of the natural products; and secondly, the attention which should be given to correct handling of these products in order to avoid deterioration during collection, transport and storage prior to extraction and utilization of the fat.

Many elegant rapid methods for the evaluation of the average characteristics of technical fats had been developed, but knowledge of their precise chemical structure was on the whole very deficient up to about twenty-five years ago. In 1924 the late Dr. E. F, Armstrong described the fats as "a neglected chapter in organic chemistry" in a presidential address to the Society of Chemical Industry, which doubtless stimulated research in this field. Certainly the constitution of natural fats is much better understood to-day; and in the United States, perhaps more than elsewhere, several centres of investigation have become known for their active work in fat chemistry.

The other feature mentioned-conservation of quality -is still too often overlooked. Many of the fat resources which Britain uses are tropical in origin. Consequently, although the fats produced in Nature are almost wholly pure triglycerides, they are liable rapidly to become rancid by enzymic hydrolysis and oxidation, unless the urgent need for guarding against such deterioration is well appreciated at the centres of collection of the raw material. Those concerned with the reception and distribution of imported fats and oil-seeds in Britain at the present time will not need to be reminded of this unfortunate condition of affairs. At any time the depreciation in value of fats produced in a high state of purity by natural processes is unnecessary and unfortunate; in periods of economic stress, it adds heavily to the burden of the manufacturer and to the difficulties of the consumer. In the whaling industry this aspect has been efficiently dealt with by use of the modern 'factory' ship; the plantation palm oil industry is also being developed with careful regard to preserva- 